\title{
Social predictors of oral hygiene status in school children from suburban Nigeria
}

\author{
Titus Ayodeje OYEDELE(a) \\ Morenike Oluwatoyin FOLAYAN(b) \\ Nneka Maureen CHUKWUMAH(c) \\ Nneka Kate ONYEJAKA ${ }^{(d)}$ \\ (a) Babcock University, School of Medicine, \\ Department of Surgery, Ilisan-Remo, Ogun \\ State, Nigeria. \\ (b) Obafemi Awolowo University, Department \\ of Child Dental Health, Ile-Ife, Nigeria \\ (c) University of Benin Teaching Hospital, \\ Benin-City Edo State, Nigeria \\ (d) University of Nigeria, Enugu, Nigeria.
}

Declaration of Interests: The authors certify that they have no commercial or associative interest that represents a conflict of interest in connection with the manuscript.

\section{Corresponding Author:}

Titus Ayodeji Oyedele

E-mail: ayotitus4christ@gmail.com

https://doi.org/10.1590/1807-3107bor-2019.vol33.0022

Submitted: April 04, 2018

Accepted for publication: January 10, 2019

Last revision: February 26, 2019
Abstract: Oral hygiene, which is measured by the status of plaquefree tooth surfaces, is essential for the promotion of oral health. This study aimed to determine the social predictors of good oral hygiene for children in a suburban population in Nigeria. This was a secondary analysis of data. The study participants were 8- to 16-year-old children who were residents in Ile-Ife, which is a suburban population in Nigeria. Information on the age, gender, socioeconomic status, family structure, number of siblings and birth rank of each study participant was retrieved from the an interviewer-administered questionnaire. Oral hygiene status was determined through a simplified-oral hygiene index (OHI-S) and categorized as good, fair and poor. The association between oral hygiene status and sociodemographic variables was determined. The predictors of good oral hygiene were determined using a binomial regression analysis. Data on 2,107 individuals were retrieved, of which $44.8 \%$ had good oral hygiene and $17.1 \%$ had poor oral hygiene. The odds of having good oral hygiene were reduced for children who were 13 to 16 years old $(p=0.02)$ or male $(P=0.002)$ and children with low socioeconomic status ( $p \leq 0.001)$. The odds of having good oral hygiene increased for children who were last-born compared with those who were first-born $(p=0.02)$. Age, gender, socioeconomic status and birth-rank were significant social predictive factors of oral hygiene status among the study population. Based on these findings, targeted interventions can be conducted to improve the oral hygiene status of children and adolescents with these social profiles.

Keywords: Oral Hygiene; Social Class; Plaque, Dental; Calculi.

\section{Introduction}

Oral hygiene represents measures taken to keep the mouth clean and healthy by maintaining plaque- and calculus-free tooth surfaces. ${ }^{1}$ The state of oral cleanliness is very important in the promotion of oral health, general health and quality of life. ${ }^{2}$ Poor oral hygiene leads to the accumulation of dental plaque, which harbors bacteria and their toxins. Bacteria plaque play an important role in the etiology of oral diseases, ${ }^{3}$ such as dental caries, ${ }^{4}$ gingivitis ${ }^{5}$ and periodontitis. ${ }^{6}$ Periodontitis resulting from poor oral hygiene is associated with the production of a significant amount of pro-inflammatory cytokines, which may 
have systemic adverse effects on the host, such as premature labor, low-birth-weight infants, ${ }^{7}$ and low sperm counts in men. ${ }^{8}$ An association has also been shown between diabetes and periodontal disease; trials have demonstrated improved glycemic control in patients with diabetes who have undergone periodontal treatment and have improved their oral hygiene. ${ }^{9}$ Hua et al. ${ }^{10}$ also demonstrated that good oral hygiene may reduce the risk of ventilation-associated pneumonia.

Multiple factors can influence oral hygiene. These include factors at the individual, family and community levels. ${ }^{11}$ Individual factors that influence oral hygiene practices and beliefs are equally influenced by family-related factors and social factors derived from communal norms, beliefs, values and practices. ${ }^{12}$

Multiple risk factors at the individual level have been identified for poor oral hygiene in children residing in Nigeria. These risk factors include socioeconomic status, age, maternal age and maternal attitude. ${ }^{13,14,15,16}$ Reports have shown that oral hygiene is poorer among children from the lower socioeconomic strata, ${ }^{13,14}$ which has also been observed in low and middle-income countries such as Tanzania ${ }^{17}$ and India. ${ }^{18}$ Birth rank, which is an identified risk factor for caries, ${ }^{19}$ may also be a risk factor for poor oral hygiene, as an association between caries and poor oral hygiene has been established. ${ }^{4}$ In addition, Agbaje et al. ${ }^{16}$ demonstrated that age was a significant determinant of oral hygiene; the older age group exhibited poorer oral hygiene when compared with the younger age group, which may be because oral hygiene supervision by parents stops when children are approximately 8 years old. In addition, women and girls have been consistently shown to exhibit a better oral hygiene status compared with their male counterparts in Nigeria. ${ }^{20}$ This finding may be because women and girls have more positive dental health attitudes and behaviors compared with their male counterparts.

The family structure and number of siblings a child has may influence the individual's oral hygiene status, as the family influences the socialization and health of an individual. ${ }^{21}$ In addition, the family structure and number of siblings a child has often reflects the socioeconomic status of the child. Children with low socioeconomic status are more likely to have more siblings and large families, ${ }^{22}$ which potentially leads to the inherent challenge of prioritizing daily living over oral health. Onyejaka et al. ${ }^{23}$ demonstrated this phenomenon in her study, in which she clearly showed that children with low socioeconomic status were significantly less likely to accept the caries-related preventive and curative services offered to them. Very little is known, however, about the effect of these family-level-related factors on the oral hygiene status of children.

Poor oral hygiene negatively impacts the quality of life. Blumenshine et al..$^{24}$ demonstrated that children with poor oral hygiene are more likely to have poor oral health and poor general health, and they are more likely to report poor school performance. Poor oral hygiene may also impact the social health and life course of children and adolescents as they grow into adulthood. In view of these sequalae, it is important to identify social variables that predict good oral hygiene for children and adolescents. ${ }^{16,25}$ Understanding how these factors influence each other may inform policy formulation and guide clinicians and health care practitioners on the appropriate guidance for populations that are vulnerable to poor oral hygiene.

This study was designed to explore the association between oral hygiene and social factors, such as family structure, birth-rank and oral hygiene status. We specifically explored the association of family structure, age, birth-rank, gender, and socioeconomic status with the oral hygiene status of children and adolescents residing in suburban Nigeria.

\section{Methodology}

\section{Study population}

This was a secondary data analysis. The primary data were generated from a cross-sectional study that recruited 2,107 children aged 8 to 16 years who were residents in the Ife Central Local Government Area of Ile-Ife, which is a suburban town in southwestern Nigeria. All children were eligible to participate in the study. Only children whose parents did not sign an informed consent form were excluded from the study. 
The data were collected over a period of 6 months between 2011 and 2012. Details of the primary study have been reported. ${ }^{26}$

\section{Sampling technique}

Study participants were selected through a multistaged sampling technique. Proportional representation of public and private schools in the sampling frame helped to ensure that children from all socioeconomic strata were recruited for the study. Enrolment into either a public or private school has been shown to be a sensitive parameter for distinguishing socioeconomic status in the study environment; children with low socioeconomic status often attend public schools, whereas those with middle and high socioeconomic status attend private schools. ${ }^{27}$ Children with high socioeconomic status attend private schools and pay higher school fees when compared with those with middle socioeconomic status. The details of the sampling methods used were reported in a prior publication by Oyedele et al. ${ }^{26}$

\section{Sample size}

The sample size was determined using the statistical formula proposed by Araoye. ${ }^{28}$ The number of study participants required for this study, based on an estimated prevalence of good oral hygiene of $18.8 \%{ }^{6}$ with a $10 \%$ attrition rate, was 235 children. However, we had access to the data on 2,107 children, thereby rendering the data robust enough to address the study objective.

\section{Collection of data}

Information on the age, gender, family structure, number of siblings, position of the child in the family and the socioeconomic status of each study participant was retrieved. The socioeconomic status of each child was determined through a multiple-item scoring inde ${ }^{29}$ that was developed from information on the mother's level of education and the father's occupation. This index has been validated in prior studies in Nigeria. ${ }^{30}$ Each child's social class was classified as follows: class I (upper class), class II (upper middle class), class III (middle class), class IV (lower middle class), or class V (lower class).

\section{Oral hygiene}

Data on the oral hygiene status of the study participants was also retrieved. Oral hygiene was recorded using the simplified-oral hygiene index (OHIS) described by Greene and Vermillion. ${ }^{31}$ This oral hygiene index has been previously used in the study environment. ${ }^{16}$ The children were examined under natural light while sitting on their school chair. To ensure privacy, children were examined in a corner of their class away from the view of other students and with access to natural visible light. Because the primary objective of the study was to screen for molar incisor hypomineralization, which may require the removal of debris for proper examination, the children were first examined for oral hygiene status prior to the removal of any debris present.

The OHI-S includes two components, namely, the debris index and the calculus index. Each component is based on numerical determinations representing the amount of debris or calculus found on the preselected tooth surfaces. The six surfaces examined for the OHI-S were selected from four posterior and two anterior teeth (upper right first molar, upper right central incisor, upper left first molar, lower left central incisor, lower left first molar and lower right first molar). The labial surfaces of the upper right first molar, upper right central incisor, upper left first molar and lower left central incisor, and the lingual surfaces of the lower right and left first molars were examined. Each tooth surface was divided into gingival, middle and incisal/occlusal thirds. The scoring was as follows: score 0 - no debris or stain present; score 1- soft debris covering not more than one-third of the tooth surface; score 2- soft debris covering not more than two-thirds of the exposed tooth surface; and score 3-soft debris covering more than two-thirds of the exposed tooth surface.

The debris index simplified score is the sum of the debris score for all teeth, divided by the number of the surfaces scored. For each child, the debris score was averaged across the 6 individual teeth to obtain a single score per child. For the simplified calculus index, the same 6 surfaces were examined and scored from 0 to 3 . Each tooth surface was divided horizontally into gingival, middle and incisal/occlusal thirds, as follows: Score 0- no calculus present; score 
1- calculus covering not more than one-third of the tooth surface; score 2- calculus covering not more than two-thirds of the exposed tooth surface; and score 3-calculus covering more than two-thirds of the exposed tooth surface. The simplified calculus index simplified is the sum of the calculus score for all teeth, divided by the number of surfaces scored. For each child, the calculus score was averaged across 6 individual teeth to obtain a single score per child.

The calculus index simplified (CI-S) and debris index simplified (DI-S) values ranged from 0 to 3 , and the OHI-S value was the sum of the CI-S and DI-; thus the score ranged from 0 to 6 . An oral hygiene index score of 0 to 1.2 was categorized as good oral hygiene; 1.3 to 2.9 was categorized as fair oral hygiene; and 3.0 to 6.0 was categorized as poor oral hygiene.

\section{Calibration of examiners}

One of the investigators underwent a calibration exercise prior to the commencement of the primary study. The calibration exercise was performed in the clinic prior to the commencement of the primary study. Intra-examiner reliability was assessed by the examination of 10 children on 2 separate occasions. The result was coded and fed into a computer. The data were then subjected to a Cohen's weighted and weighted kappa scores analysis to determine intraexaminer reliability. The intra-examiner reliability score for $\mathrm{OH}$ was 0.95 .

\section{Data analysis}

The socioeconomic status of the children was separated into three groups during data entry, as follows: classes I and II were classified as high socioeconomic status; class III was classified as middle socioeconomic status; and classes IV and V were classified as low socioeconomic status. The study participants were also grouped into the following two age groups: those in the mixed dentition stage ( 8 to 12 years) and those in the permanent dentition stage (13 to 16 years).

Associations between age, gender, socioeconomic status, birth rank, number of siblings, family structure and oral hygiene status were determined using the chi-square analysis. Birth rank was grouped as follows: first-born, last-born and others.
Age was dichotomized into the following two groups: 8 to 12 years, representing those with mixed dentition; and 13 to 16 years, representing those with permanent dentition. Number of siblings was classified into the following three groups: 0 to 1,2 to 4 , and more than 4 . This classification has been used previously in the study environment. ${ }^{32}$ The national policy on family planning advises parents to limit the number of children to four. Many homes in Nigeria therefore consider a family size of four to be ideal. However, many families in the high socioeconomic status bracket have fewer children. The number of children may therefore be an indication of socioeconomic status.

The predictors of good, fair and poor oral hygiene were determined using a binomial regression analysis that adjusted for age, gender, socioeconomic status, birth rank, number of sibling and family structure. However, oral hygiene was dichotomized into two groups by merging fair and poor oral hygiene and reclassifying these groups as poor oral hygiene. Good oral hygiene remained its own group. This categorization has been used in a prior study. ${ }^{16}$ The reference groups in the model were women, children with high socioeconomic status, children aged 8 to 12 years (mixed dentition stage), first-born children, children with a single sibling, and children with both parents. ${ }^{2}$ All variables were included in the logistic regression models as potential determinants for oral hygiene status. The statistical analysis was conducted using STATA version 11.0. Statistical significance was established at $p$ values equal to or less than 0.05 .

\section{Ethical consideration}

Ethical approval for the study was obtained from the Ethics and Research committee of the Obafemi Awolowo University Teaching Hospital (ERC/2011/06/03). Permission to conduct studies in the schools was obtained from the Education Ministry and Heads of all schools that participated in the study. Written informed consent for child participation in the study was obtained from the parents and legal guardians of the children. Consent was obtained from participating children who are older than 12 . 
Table 1. Sociodemographic variables of the study participants with various degree of oral hygiene $(n=2,107)$.

\begin{tabular}{|c|c|c|c|c|c|c|c|c|}
\hline \multirow{3}{*}{$\begin{array}{l}\text { Oral } \\
\text { hygiene }\end{array}$} & \multicolumn{2}{|c|}{ Age (years) } & \multicolumn{2}{|c|}{ Gender } & \multicolumn{4}{|c|}{ Socioeconomic status } \\
\hline & $8-12$ & $13-16$ & Female & Male & High & Middle & Low & Total \\
\hline & n (\%) & n (\%) & $n(\%)$ & n (\%) & $n(\%)$ & $n(\%)$ & n (\%) & $\mathrm{n}(\%)$ \\
\hline Good & $577(46.7)$ & $366(42.0)$ & $542(48.2)$ & $401(40.8)$ & $315(51.3)$ & $224(47.3)$ & $404(39.6)$ & $943(44.7)$ \\
\hline Fair & $460(37.2)$ & $344(39.4)$ & $425(37.8)$ & $379(38.6)$ & $191(31.1)$ & 191 (40.3) & $400(39.3)$ & $804(38.2)$ \\
\hline Poor & $198(16.1)$ & $162(18.6)$ & $158(14.0)$ & $202(20.6)$ & $59(9.6)$ & $59(12.4)$ & $215(21.1)$ & $360(17.1)$ \\
\hline Total & $1,235(58.6)$ & $872(41.4)$ & $1,125(53.4)$ & $982(46.6)$ & $614(29.1)$ & $474(22.5)$ & $1,019(48.4)$ & $2,107(100$ \\
\hline$x^{2}$ & \multicolumn{2}{|c|}{7.20} & \multicolumn{2}{|c|}{19.48} & \multicolumn{3}{|c|}{34.29} & \\
\hline$p$-value & \multicolumn{2}{|c|}{0.027} & \multicolumn{2}{|c|}{$\leq 0.001$} & \multicolumn{3}{|c|}{$\leq 0.001$} & \\
\hline
\end{tabular}

Table 2. Social predictors associated with oral hygiene in lle-lfe, Nigeria ( $n=2,107)$.

\begin{tabular}{|c|c|c|c|c|c|c|c|c|c|c|}
\hline \multirow[b]{2}{*}{ Variable } & \multicolumn{3}{|c|}{ Family structure } & \multicolumn{3}{|c|}{ Birth rank } & \multicolumn{4}{|c|}{ Number of siblings } \\
\hline & $\begin{array}{l}\text { Both } \\
\text { parents } \\
\mathrm{n}(\%)\end{array}$ & $\begin{array}{c}\text { Single } \\
\text { parent } \\
n(\%)\end{array}$ & $\begin{array}{c}\text { Other forms } \\
\text { of parenting } \\
n(\%)\end{array}$ & $\begin{array}{c}\text { First-born } \\
n(\%)\end{array}$ & $\begin{array}{c}\text { Last-born } \\
\mathrm{n}(\%)\end{array}$ & $\begin{array}{c}\text { Others } \\
n(\%)\end{array}$ & $\begin{array}{l}1 \text { sibling } \\
\mathrm{n}(\%)\end{array}$ & $\begin{array}{c}2-4 \\
\text { siblings } \\
\mathrm{n}(\%)\end{array}$ & $\begin{array}{c}>4 \\
\text { siblings } \\
n(\%)\end{array}$ & Total n(\%) \\
\hline $\begin{array}{l}\text { Good oral } \\
\text { hygiene }\end{array}$ & $\begin{array}{c}774 \\
(45.4)\end{array}$ & $\begin{array}{c}104 \\
(46.8)\end{array}$ & $\begin{array}{c}65 \\
(36.3)\end{array}$ & $\begin{array}{c}291 \\
(42.7)\end{array}$ & $\begin{array}{c}255 \\
(50.0)\end{array}$ & $\begin{array}{c}397 \\
(43.3)\end{array}$ & $\begin{array}{c}21 \\
(55.3)\end{array}$ & $\begin{array}{c}614 \\
(44.2)\end{array}$ & $\begin{array}{c}308 \\
(45.2)\end{array}$ & $\begin{array}{c}943 \\
(44.8)\end{array}$ \\
\hline $\begin{array}{l}\text { Fair oral } \\
\text { hygiene }\end{array}$ & $\begin{array}{c}647 \\
(37.9)\end{array}$ & $\begin{array}{c}81 \\
(36.5)\end{array}$ & $\begin{array}{c}76 \\
(42.5)\end{array}$ & $\begin{array}{c}260 \\
(38.2)\end{array}$ & $\begin{array}{c}188 \\
(36.9)\end{array}$ & $\begin{array}{c}356 \\
(38.9)\end{array}$ & $\begin{array}{c}13 \\
(34.2)\end{array}$ & $\begin{array}{c}547 \\
(379.4)\end{array}$ & $\begin{array}{c}244 \\
(35.8)\end{array}$ & $\begin{array}{c}804 \\
(38.2)\end{array}$ \\
\hline $\begin{array}{l}\text { Poor oral } \\
\text { hygiene }\end{array}$ & $\begin{array}{c}285 \\
(16.7)\end{array}$ & $\begin{array}{c}37 \\
(16.7)\end{array}$ & $\begin{array}{c}38 \\
(21.2)\end{array}$ & $\begin{array}{c}130 \\
(19.1)\end{array}$ & $\begin{array}{c}67 \\
(13.1)\end{array}$ & $\begin{array}{c}163 \\
(17.8)\end{array}$ & $\begin{array}{c}4 \\
(10.5)\end{array}$ & $\begin{array}{c}227 \\
(16.4)\end{array}$ & $\begin{array}{c}129 \\
(18.9)\end{array}$ & $\begin{array}{c}360 \\
(17.1)\end{array}$ \\
\hline Total & $\begin{array}{l}1,706 \\
(81.0)\end{array}$ & $\begin{array}{c}222 \\
(10.5)\end{array}$ & $\begin{array}{l}179 \\
(8.5)\end{array}$ & $\begin{array}{c}681 \\
(32.3)\end{array}$ & $\begin{array}{c}510 \\
(24.2)\end{array}$ & $\begin{array}{c}916 \\
(43.5)\end{array}$ & $\begin{array}{c}38 \\
(1.8)\end{array}$ & $\begin{array}{l}1,388 \\
(65.9)\end{array}$ & $\begin{array}{c}681 \\
(32.3)\end{array}$ & $\begin{array}{c}2,107 \\
(100.0)\end{array}$ \\
\hline$x^{2}$ & & 6.23 & & & 11.04 & & & 5.51 & & \\
\hline $\mathrm{p}$-value & & 0.18 & & & 0.02 & & & 0.24 & & \\
\hline
\end{tabular}

\section{Results}

Table 1 shows the age, gender and socioeconomic status of the 2,107 study participants. A total of 1,125 participants (53.4\%) were female, $943(44.7 \%)$ had good oral hygiene and $360(17.1 \%)$ had poor oral hygiene. A total of 1,235 (58.6\%) were 8 to 12 years old, while $872(41.4 \%)$ were 13 to 16 years old.

In addition, $46.7 \%$ children in the age group of 8 to 12 years had good oral hygiene, while $16.1 \%$ had poor oral hygiene. There was a higher percentage of children with poor oral hygiene in the age group of 13 to 16 years compared to those in the younger age group (18.6\% vs $16.1 \%)$. The association between oral hygiene status and age was statistically significant $(p=0.025)$. In addition, $542(48.2 \%)$ females and 315 (51.3\%) children with high socioeconomic status had good oral hygiene. Significantly more female than male children $(p<0.001)$, and more children with high socioeconomic status compared with those with middle and low socioeconomic status $(\mathrm{p}<0.001)$ had good oral hygiene.

Table 2 shows the social factors that were associated with oral hygiene status. The association between oral hygiene status and birth rank was statistically significant $(p=0.02)$; a larger proportion of children that were the last-born had good oral hygiene. No significant association was detected between oral hygiene status, number of siblings $(p=0.24)$, and family structure $(p=0.18)$.

Table 3 shows the results of the regression analysis that was performed to determine the predictors of good oral hygiene for the study participants. The following four parameters were shown to be predictors of good oral hygiene: age, gender, socioeconomic status and birth rank. Children in the age group of 13 to 16 years had reduced odds of having good oral 
Table 3. Logistic regression determining the odds of having good oral hygiene among all study participants $(n=2,107)$.

\begin{tabular}{|c|c|c|c|}
\hline Variable & Adjusted OR & $95 \%$ C.I. & $\mathrm{p}$-value \\
\hline \multicolumn{4}{|l|}{ Age (years) } \\
\hline $8-12$ & 1 & - & - \\
\hline $13-16$ & 0.82 & $0.68-0.98$ & 0.02 \\
\hline \multicolumn{4}{|l|}{ Gender } \\
\hline Female & 1 & - & - \\
\hline Male & 0.76 & $0.64--0.91$ & 0.002 \\
\hline \multicolumn{4}{|l|}{ Socioeconomic status } \\
\hline High & 1 & - & - \\
\hline Middle & 0.88 & $0.69-1.12$ & 0.30 \\
\hline Low & 0.64 & $0.52-0.79$ & $\leq 0.001$ \\
\hline \multicolumn{4}{|l|}{ Birth rank } \\
\hline First-born & 1 & - & - \\
\hline Last-born & 1.33 & $1.04-1.69$ & 0.02 \\
\hline Others & 1.03 & $0.83-1.28$ & 0.81 \\
\hline \multicolumn{4}{|l|}{ Number of siblings } \\
\hline $0-1$ & 1 & - & - \\
\hline $2-4$ & 0.63 & $0.32-1.25$ & 0,19 \\
\hline$>4$ & 0.71 & $0.36-1.43$ & 0.34 \\
\hline \multicolumn{4}{|l|}{ Family structure } \\
\hline Both parents & 1 & - & - \\
\hline Single parent & 1.10 & $0.83-1.47$ & 0.50 \\
\hline Living with others & 0.75 & $0.53-1.04$ & 0.09 \\
\hline
\end{tabular}

hygiene compared with those in the age group of 8 to 12 years $(p=0.025)$. Males were more likely to have poor oral hygiene compared with females $(p=0.002)$. In addition, children with low socioeconomic status had reduced odds of having good oral hygiene compared with those with high socioeconomic status ( $p \leq 0.001)$. However, children who were the last-born had increased odds of having good oral hygiene when compared with those who were first-born $(p=0.02)$.

\section{Discussion}

This study identified the following four social predictors for good oral hygiene for a population of children who reside in suburban Nigeria: age, gender, socioeconomic status and birth rank. Young children, female children, those with high socioeconomic status and those who were last-born were more likely to have good oral hygiene. These results are similar to the results of prior studies conducted in Nigeria, other African countries and other countries outside of Africa.

Prior studies conducted in Nigeria ${ }^{13,14}$ and other parts of the world ${ }^{20}$ have shown that oral hygiene status deteriorates as the socioeconomic status decreases, just as oral health decreases with socioeconomic status. ${ }^{33}$ The links between low socioeconomic status and poor oral hygiene are multiple. First, low socioeconomic status is linked with low financial capacity - including poor access to insurance - thus limiting access to oral hygiene tools and access to dental care services. ${ }^{34}$ Second, people with low socioeconomic status have an increased predisposition for multiple health and social problems, which creates mental stress and a resultant low prioritization of oral hygiene practices. ${ }^{34}$ Third, people with low socioeconomic status also have low oral health literacy, which is associated with poor knowledge, attitudes and practices of oral hygiene. ${ }^{35}$

Busby et al. ${ }^{36}$ showed that oral health generally tends to decline with age. We showed that oral hygiene status was poorer for older children. Oral hygiene supervision stops when children are approximately 8 years of age. ${ }^{37}$ One would assume that this transition to independency, and the discomfort associated with tooth exfoliation and new tooth eruption in the mixed dentition stage should result in worse oral hygiene for children who are 8 to 12 years old compared to younger counterparts. Therefore, the observation that children in the later stage of their permanent dentition years have poorer hygiene is surprising and has many implications for their adult years. This finding implies that critical actions needs to be taken in the teenage years to enable children to acquire improved oral hygiene practices, as poor oral hygiene increases the risk for caries ${ }^{4}$ in addition to other oral and general health problems. ${ }^{2}$ The findings of this study imply that policy and regulatory actions need to be taken to safeguard the future oral and general health of the study population, with an emphasis on a life-course approach to health management in the study population. ${ }^{38}$ This need arises because oral and general health habits are acquired early in adolescence. ${ }^{39}$ 
The two other social factors that predict oral hygiene status - gender and birth rank - are more difficult to ameliorate through policies. Girls have been shown in the study environment to have better oral hygiene than boys. ${ }^{6}$ Multiple studies have demonstrated that women have more positive dental health attitudes and behaviors compared with men; in addition, women make more regular visits to the dentist and spend more time with tooth brushing, brush more frequently and use dental floss..$^{23,40}$ There was, however, a study that showed no gender difference in oral hygiene status. ${ }^{40}$ We have no viable explanation for these contradictory observations. However, we postulate that female children in Nigeria may be more conscious of their aesthetic and oral hygiene and may therefore take oral hygiene more seriously compared with male children. Birth rank is a recognized risk factor for caries ${ }^{19}$ and, in this study, birth rank was shown to be a risk factor for poor oral hygiene. In addition, children who are the last-born receive improved attention to their oral and general health when compared with children with other birth ranks. These postulations warrant further exploration and testing.

This study provides insight into the fact that oral hygiene is poorer for younger children with low socioeconomic status, those who are first-born and those who are males. Children with these profiles are therefore vulnerable to poor oral health and should be targeted for oral hygiene interventions. This finding is important, as children with poor oral hygiene often have poor oral and general health and are more likely to report poor school performance. ${ }^{20}$

One of the strengths of this study is the large sample size, which allowed for a robust analysis. Second, the recruitment process ensured the appropriate representation of all socioeconomic class in the sampling process. However, this study did not include children younger than 8 years old, which limited the ability to show a trend towards poorer oral hygiene status with increasing age. Additionally, the study participants were recruited from a suburban town in Ile-Ife, which limited the generalizability of the study findings to Nigeria. In addition, oral hygiene of the children was assessed while they were sitting on a chair in their various classes. This methodology may have affected the assessment of oral hygiene status. Finally, frequent tooth brushing and the use of an interdental brush and dental floss, which have been shown to impact oral hygiene, ${ }^{16,25}$ were not considered in this study.

\section{Conclusion}

A larger proportion of children in this study environment exhibited good oral hygiene. The following four social predisposing factors for good oral hygiene were identified in the study population: being in the younger age group, being female, having a high socioeconomic status and being the last-born child in the family. The findings of this study should be interpreted with caution, bearing in mind that this study was limited to a subpopulation of children in Nigeria. Policies and programs can promote the institution of preventive measures that reduce health and socioeconomic status disparities which negatively impact oral hygiene status and oral health. Further studies are warranted to investigate the underlying reasons explaining why gender and birth-rank are predictors of good oral hygiene.

\section{Acknowledgement}

The authors acknowledge the parents and pupils that participated in the study and the Ethics and Research Committee of Obafemi Awolowo University Teaching Hospital Complex for the ethical approval.

\section{References}

1. Miller-Keane encyclopedia and dictionary of medicine, nursing, and allied health, $7^{\text {th }}$ ed. St. Louis: Saunders, 2003.

2. Petersen PE. The World Oral Health Report 2003: continuous improvement of oral health in the 21 st century-the approach of the WHO Global Oral Health Programme. Community Dent Oral Epidemiol. 2003 Dec;31 (s1 Suppl 1):3-23. https://doi.org/10.1046/i..2003.com122.x

3. World Health Organization - WHO. Oral health. Geneva: World Health Organization; 2018. 
4. Bhayat A, Ahmad MS, Hifnawy T, Mahrous MS, Al-Shorman H, Abu-Naba'a L, et al. Correlating dental caries with oral bacteria and the buffering capacity of saliva in children in Madinah, Saudi Arabia. J Int Soc Prev Community Dent. 2013 Jan;3 (1):38-43. https://doi.org/10.4103/2231-0762.115712

5. Gurenlian JR. The role of dental plaque biofilm in oral health. J Dent Hyg. 2007 Oct;81 (5):1-11.

6. Ogunsile SE, Ojo I. Oral hygiene status of adolescents in a local government area of Oyo State Nigeria. J Sci Technol. 2010 Dec;30 (3):81-6.

7. Saini R, Saini S, Saini SR. Periodontitis: A risk for delivery of premature labor and low-birth-weight infants. J Nat Sci Biol Med. 2010 Jul;1 (1):40-2. https://doi.org/10.4103/0976-9668.71672

8. Nwhator SO, Umeizudike KA, Ayanbadejo PO, Opeodu OI, Olamijulo JA, Sorsa T. Another reason for impeccable oral hygiene: oral hygiene-sperm count link. J Contemp Dent Pract. 2014 May;15 (3):352-8. https://doi.org/10.5005/ip-journals-10024-1542

9. Lakschevitz F, Aboodi G, Tenenbaum H, Glogaver M. Diabetes and periodontal diseases: interplay and links. Curr Diabetes Rev. 2011 Nov;7 (6):433-9. https://doi.org/10.2174/157339911797579205

10. Hua F, Xie H, Worthington HV, Furness S, Zhang Q, Li C. Oral hygiene care for critically ill patients to prevent ventilator-associated pneumonia. Cochrane Database Syst Rev. 2016 Oct;10:CD008367. https://doi.org/10.1002/14651858.CD008367.pub3

11. Castilho AR, Mialhe FL, Barbosa TS, Puppin-Rontani RM. Influence of family environment on children's oral health: a systematic review. J Pediatr (Rio J). 2013 Mar-Apr;89 (2):116-23. https://doi.org/10.1016/i.jped.2013.03.014

12. Jain G, Kawadkar A, Moidin T, Singhal V, Chouksey A. Assessment of oral hygiene habits among the dental students of bhopal, madhya pradesh: a questionnaire survey. J Orofac Res. 2013;3:249-52. https://doi.org/10.5005/ip-journals-10026-1105

13. Noah MO. Caries experience and state of oral cleanliness in 4 -year-old lbadan children attending private schools. J Int Assoc Dent Child. 1981 Jan;12 (1):17-23.

14. Sofola OO, Shabar OP, Jeboda SO. Oral hygiene and periodontal treatment needs of urban school children compared with those of rural school children in Nigeria. Afr Dent J. 1994;8:20-5.

15. Abiola Adeniyi A, Eyitope Ogunbodede O, Sonny Jeboda O, Morenike Folayan O. Do maternal factors influence the dental health status of Nigerian pre-school children? Int J Paediatr Dent. 2009 Nov;19 (6):448-54. https://doi.org/10.1111/j.1365-263X.2009.01019.x

16. Agbaje HO, Kolawole KA, Folayan MO, Onyejaka NK, Oziegbe EO, Oyedele TA, et al. Digit sucking, age, sex, and socioeconomic status as determinants of oral hygiene status and gingival health of children in Suburban Nigeria. J Periodontol. 2016 Sep;87 (9):1047-56. https://doi.org/10.1902/jop.2016.150681

17. Frenken JE, Truin G-J, Hot MA, König KG, Lembariti BS, Mulder J et al. Plaque, calculus, gingival bleeding and type of tooth cleaning devise in a Tanzanian child population 1984,1986,1988. J Clin Periodontol. 1991;8:592-7. https://doi.org/10.1111/j.1600-051X.1991.tb00095.x

18. Sogi GM, Bhaskar DJ. Dental caries and oral hygiene status of school children in Davangere related to their socio-economic levels: an epidemiological study. J Indian Soc Pedod Prev Dent. 2002 Dec;20 (4):152-7.

19. Folayan MO, Owotade F, Oziegbe EO, Fadeyibi R. Effect of birth rank on the caries experience of children from a suburban population in Nigeria. J Dent Oral Hyg. 2010;2:27-30.

20. Olabisi AA, Udo UA, Ehimen UG, Bashiru BO, Gbenga OO, Adeniyi AO. Prevalence of dental caries and oral hygiene status of a screened population in Port Harcourt, Rivers State, Nigeria. J Int Soc Prev Community Dent. 2015 Jan-Feb;5 (1):59-63. https://doi.org/10.4103/2231-0762.151979

21. Richards MH, Gitelson IB, Peterson AC, Hurtig AL. Adolescent personality in girls and boys: the role of mothers and fathers. Psychol Women Q. 1991;15 (1):65-81. https://doi.org/10.1111/j.1471-6402.1991.tb00478.x

22. Al-Agha AE, Tatwany BO, Aiash DA, Mandourah LA, Abukhalil NT. The effect of socioeconomic status, number of siblings and parental of education on children' body mass index at Jeddah, Saudi Arabia: cross sectional study. Fam Med Med Sci Res. 2015;4 (05):184. https://doi.org/10.4172/2327-4972.1000184

23. Onyejaka NK, Folayan MO, Folaranmi N. Barriers and facilitators of dental service utilization by children aged 8 to 11 years in Enugu State, Nigeria. BMC Health Serv Res. 2016 Mar;16 (1):93. https://doi.org/10.1186/s12913-016-1341-6

24. Blumenshine SL, Vann WF Jr, Gizlice Z, Lee JY. Children's school performance: impact of general and oral health. J Public Health Dent. 2008;68 (2):82-7. https://doi.org/10.1111/j.1752-7325.2007.00062.x

25. Kolawole KA, Oziegbe EO, Bamise CT. Oral hygiene measures and the periodontal status of school children. Int J Dent Hyg. 2011 May;9 (2):143-8. https://doi.org/10.1111/j.1601-5037.2010.00466.x

26. Oyedele TA, Folayan MO, Adekoya-Sofowora CA, Oziegbe EO. Co-morbidities associated with molar-incisor hypomineralisation in 8 to 16 year old pupils in Ile-Ife, Nigeria. BMC Oral Health. 2015 Mar;15 (1):37. https://doi.org/10.1186/s12903-015-0017-7

27. Ojofeitimi EO, Owolabi OO, Aderonmu A, Esimai AO, Olasanmi SO. A study on under five nutritional status and its determinants in a semi-rural community of Ile-Ife, Osun State, Nigeria. Nutr Health. 2003;17 (1):21-7. https://doi.org/10.1177/026010600301700103

28. Araoye MO. Research methodology with statistics for health and social science. Ilorin, Nigeria: Nathadex; 2003.

29. Bernard B. Indices of social classification. In: Merton RK. Social stratification: a comparative analysis of structure and process. 2nd ed. New York: Harcourt Brace; 1957 p. 78-185. 
30. Olusanya O, Okpere O, Ezimokhai M. The importance of social class in voluntary fertility control in developing country. West Afr J Med. 1985;4:205-12.

31. Greene JC, Vermillion JR. The simplified oral hygiene index. J Am Dent Assoc. 1964 Jan;68 (1):7-13. https://doi.org/10.14219/jada.archive.1964.0034

32. Oyedele TA, Kilelomo K, Folayan M, Agbaje H, Oziegbe E, Onyejaka N, et al. Family structure and oral habits among children age 1 to 12 years resident in Ile-Ife, Nigeria. Braz J Oral Sci. 2016;15 (4):287-92. https://doi.org/10.20396/bjos.v15i4.8650041

33. Locker D, Frosina C, Murray H, Wiebe D, Wiebe P. Identifying children with dental care needs: evaluation of a targeted school-based dental screening program. J Public Health Dent. 2004;64 (2):63-70. https://doi.org/10.1111/j.1752-7325.2004.tb02729.x

34. Wall T, Nasseh K, Vujicic M. Most important barriers to dental care are financial, not supply related. Health Policy Institute Research Brief. American Dental Association. October 2014 [cited 2017 May 18]. Available from: http://www.ada.org/ /media/ADA/Science\%20 and\%20Research/HPI/Files/HPIBrief_1014_2.ashx

35. Paul B, Basu M, Dutta S, Chattopadhyay S, Sinha D, Misra R. Awareness and practices of Oral hygiene and its relation to sociodemographic factors among patients attending the general outpatient department in a tertiary care hospital of Kolkata, India. J Family Med Prim Care. 2014 Apr;3 (2):107-11. https://doi.org/10.4103/2249-4863.137611

36. Busby M, Martin JA, Matthews R, Burke FJ, Chapple I. The relationship between oral health risk and disease status and age, and the significance for general dental practice funding by capitation. Br Dent J. 2014 Nov;217 (10):E19. https://doi.org/10.1038/sj.bdj.2014.1006

37. American Academy of Pediatric Dentistry. Fast facts. 2014 [cited 2017 Apr 18]. https://www.aapd.org/assets/1/7/fastfacts.pdf

38. World Health Organization - WHO. A life course approach to health. 2000 [cited 2017 May 17]. Available from: https://www.who.int/.../ lifecourse/alc_lifecourse_training_en

39. American Academy of Pediatric Dentistry. Guideline on adolescent oral health care. 2015 [cited 2017 May 22]. Available from: https://www.aapd.org/media/policies.../g_adoleshealth.pdf

40. Mamai-Homata E, Koletsi-Kounari H, Margaritis V. Gender differences in oral health status and behavior of Greek dental students: a meta-analysis of 1981, 2000, and 2010 data. J Int Soc Prev Community Dent. 2016 Jan-Feb;6 (1):60-8.

https://doi.org/10.4103/2231-0762.175411 
Social predictors of oral hygiene status in school children from suburban Nigeria. Braz Oral Res. 2019;33:e022.

\author{
Author's name \\ Where is read: Titus Ayodele Oyedele \\ It should read: Titus Ayodeje Oyedele
}

